\title{
SOETOMO SCORE AS A PREDICTOR OF HIV-ASSOCIATED NEUROCOGNITIVE DISORDERS
}

\author{
Running head: Soetomo Score and HIV-Associated Neurocognitive Disorders \\ ${ }^{1}$ Fajar Rudy Qimindra, ${ }^{2}$ Muhammad Hamdan, ${ }^{2}$ Riani Wisnujono, ${ }^{2}$ Yudha Haryono, \\ ${ }^{2}$ Abdulloh Machin
}

\begin{abstract}
Background HIV-Associated Neurocognitive Disorders (HAND)wasone of theneurological complicationsof HIVinfection. However, there were no biomarkers have been sufficiently validated for prognosis
\end{abstract} HAND.

Objective: To develop a scoring system and determine prognostic values of Soetomo Score as Predictor of HIVAssociated Neurocognitive Disorders (SSP HAND).

Methods: The case-control study was performed at the UPIPI out-patient clinic. The examination is performed using MoCa-Ina.Eight parameters which were possible to be a predictor of HAND were analyzed by bivariate and multivariate. Results were analyzed using calibration test and discrimination test produced Area Under Curve (AUC) value. The cut-off point could make identification of good and bad prognostics.

Results: The equation of SSP HAND was Y=-4.164+1.249 score total of SSP HAND. AUC value of this score was $80.9 \%$ (95\% CI=71.1\%-90.6\%). The value of SSP HAND was $\geq 3.5$,it means that the sensitivity was $74,4 \%$ and the specificity was79.5\%. Subject with score 0-3 had good prognostic while score 4-5 had bad prognostic.

Conclusion: Value of SSP HAND $\geq 3.5$ could make a good prediction of HAND.

Keywords---Soetomo score, Neurocognitive disorder, Prognostic test

\section{INTRODUCTION}

Human Immunodeficiency Virus (HIV) infection has become an epidemic worldwide including in Indonesia. The Ministry of Health of the Republic of Indonesia reported the number of HIV and Acquired Immunodeficiency Syndrome (AIDS) cases cumulatively in 33 provinces and 300 districts/cities in Indonesia until September 2014 was 150,296 and 55,799 cases respectively. Incident of HIV and AIDS was 22,869 and 1,876 AIDS cases. The cumulative number of national AIDS cases is 16.59 per 100,000 population and East Java ranks second after DKI Jakarta $(1,2)$.

The discovery of antiretroviral drugs (ARVs) in 1996 led to a revolution in the treatment of people living with HIV and AIDS. Although it has not been able to cure the disease, ARV therapy dramatically reduces mortality, morbidity, and improves the quality of life of people living with HIV. On the other hand, the number of HIV-Associated Neurocognitive Disorders (HAND) increased sharply. It is estimated that the HAND prevalence is 40-70\% (3-

\footnotetext{
${ }^{1_{1}}$ Department of Neurology, Faculty of Medicine, Dr. Soetomo General Hospital, Universitas Airlangga, Surabaya

${ }^{2}$ Department of Neurology, Faculty of Medicine, Dr. Soetomo General Hospital, Universitas Airlangga, Surabaya

Jalan Mayjen Prof.Dr.Moestopo 6-8, Surabaya, Indonesia 60285.

Email: muhammadhamdan.md@gmail.com
} 
International Journal of Psychosocial Rehabilitation, Vol. 24, Issue 02, 2020

ISSN: $1475-7192$

6)among HIV patients. There are three reasons why HAND has been the subject of discussion in the past decade. First, HIV becomes a chronic disease with a physical condition that almost approached a normal person. Second, there is an increase in life expectancy in HIV patients so that it can survive to older age. Third, although ARV therapy is very effective in reducing viral replication and restoring immune function, HAND is still high prevalence (3-6).

To our knowledge, there is no biomarker for the prognosis of HAND incidence.Therefore, scoring model is needed to predict cognitive impairment in HIV patients.There have been several prognostic scores that calculate the incidence of dementia in general. Such scores are common with reference to the incidence of cognitive impairment alone $(7,8)$.But there is no cognitive impairment score on HAND that involves specific predictors of HIV infection such as duration of ART, the number of CD4 lymphocyte, and CNS opportunistic infections. This specific scoring model has been successfully established in diabetes mellitus by taking into account the specific predictors of diabetes mellitus (7-9).

This study aimed to develop a scoring model with good prognostic value in predicting cognitive impairment in HIV, called as the Soetomo Score for a Predictor of Cognitive Disorder in HIV Infection (SSP GKH).It consists of predictor parameters of cognitive impairment in HIV patients including age, education level, duration of ART, gender, CD4T lymphocytes, vascular risk factors, CNS opportunistic infections, and body mass index (BMI).

The predictor parameters of cognitive impairment in SSP GKH are obtained from all subjects of HIV patients to be analyzed according to prognostic studies with categorical outcomes. The analysis consists of descriptive analysis, bivariate statistics, multivariate statistics, model selection and scoring system (10).

\section{METHODS}

Design and Location Research

Case control was used as design of this study. The design examines the relationship between exposure and disease by comparing the case group and control group based on their exposure status. The study population was all HIV patients receiving ART in HIV polyclinic of Dr.Soetomo General Hospital. Affordable populations are all HIV patients receiving antiretroviral therapy in HIV polyclinic of Dr.Soetomo General Hospitalfrom September 2015 to December 2015who fulfilled the criteria of inclusion and exclusion.

\section{Population Research}

The inclusion criteria in this study were HIV positive patients who were diagnosed by performing a 3-method test; MOCA-Ina examination results show abnormalities; currently on ART treatment, patients aged 17 and older; and patients who are cooperative and willing to be included in the study by signing an informed consent.Exclusion criteria were HIV patients with GCS less than 456 and patients who can not read and write.

Chi-square test is used for bivariate statistical analysis on all variables with categorical measurement scale anddetermine odds ratio. We performed logistic regression with backward stepwise method. The determination of the cut-off point to make predictions of cognitive impairment in HIV patients will be done from all CNS GKH values obtained from all subject patients. 
International Journal of Psychosocial Rehabilitation, Vol. 24, Issue 02, 2020

ISSN: $1475-7192$

\section{RESULTS}

The process of data collection of research subjects was conducted from November to December 2015. In all subjects, demographic and clinical data were recorded. All subjects underwent examination of MoCA-Ina at UPIPI outpatent clinic of Dr. Soetomo General Hospital Surabaya.

Total of 78 subjects was divided into 39 normal subjects with normal MoCA-Ina examination results that called as control group and 39 subjects with abnormal MoCA-Ina examination results hereinafter referred to as case group.

\section{Demographic Data}

Demographic data of study subjects covering age, sex and education can be seen in table 1.We found 19 men (42.2\%) in the case group less than the control group of 26 men (57.8\%). There was a difference of sex proportions between each group, but this difference was not statistically significant with $\mathrm{p}=0.109$ (table 1).We obtained 14 people aged 40 years and over (35.9\%) in the case group higher than the control group of 12 people aged over 40 years (30.8\%). There was a difference in the proportion of age between each group, but this difference was not statistically significant with $\mathrm{p}=0.631$ (table 1 ).

In the case group, it was found that 37 people had received 12 years compulsory education (94.9\%), more than the control group consisting of 29 people had received 12 years compulsory education (74.4\%). There was a difference in the proportion of educational levels between each group and this difference was statistically significant with $\mathrm{p}=0.012$ (table 1).

\section{Clinical Data}

From the data collected, there were clinical data including BMI, number of T-cell lymphocytes at nadir, duration of ART therapy, CNS opportunistic infections, history of vascular risk to be predictors of SSP GKH. BDI scores are also done to rule out major depressive disorders. Clinical data of research subjects can be seen in table 2 .

\section{SSP GKH Parameters}

Eight candidate of SSP GKH parameters include: age, sex, education level, duration of ART, CD4 T lymphocyte count, vascular risk factors, CNS opportunistic infections, and body mass index (BMI).Bivariate analysis was done by Chi-square test. Crosstab performed between eight candidates of SSP GKH variable with MOCA-Ina score. The analysis resulted an Odds Ratio with 95\% CI and a p value of each parameter. Variables with OR $>1$ and p value $<0.25$ in bivariate analysis will be tested using multivariate analysis (Table 3).

Six of the eight candidate SSP GKH variables were predictors of cognitive impairment, namely: gender ( $\mathrm{OR}=2.11$, 95\% CI=0.84-5.26), education level ( $\mathrm{OR}=6.38$, 95\% $\mathrm{CI}=1.29-31.41)$, duration of ART (OR=3.053, 95\% CI=1.167.93), number of CD4 lymphocyte ( $\mathrm{OR}=4,138 ; 95 \% \mathrm{CI}=1.041-16.44)$, and opportunistic infections of CNS (OR=6,38; 95\% CI=1.29-31.41) (table 3). The six parameters were further analyzed by multivariate analysis.

Logistic regression analysis was used in multivariate analysis with dependent variable of categorical dichotomes in case control research. Logistic regression method used is backward stepwise method. (Table 4).

The results showed that only four parameters were statistically significant $(\mathrm{p}<0.05)$ as a predictor of cognitive impairment in HIV, ie: educational level, CD4 T lymphocytes, CNS opportunistic infections, and duration of antiretroviral therapy. These four parameters will become the prognostic model of SSP GKH. 
International Journal of Psychosocial Rehabilitation, Vol. 24, Issue 02, 2020

ISSN: $1475-7192$

\section{Accuracy of Prognostic Models}

The accuracy of the prognostic model depends on the value of calibration and discrimination. In the prognostic model with categorical form output, calibration values were tested by Hosmer and Lemeshow test while discriminatory values were tested with Area Under the Curver (AUC)(10). The value of discrimination is tested with the Receiver Operating Characteristic (ROC) procedure. From this procedure, we get the value of Area Under Curve (AUC) SSP GKH of 80.9\% (95\% CI = 71.1\% - 90.6\%) (Figure 2).

The ROC procedure also produces some alternative cutoff points from the GKH SSP along with their sensitivity values then followed by the calculation of specificity values. Table 6 shows the sensitivity and specificity values at some of the points of intersection. The optimal cutoff point obtained from the intersection of the sensitivity curve and the specificity curve. The point obtainedwas $\geq 3.5$ (figure 3 ) with sensitivity of $74.4 \%$ and a specificity of $79.5 \%$ (table 5).The closest number which is greater than 3.5 is 4 . It means thatthe subject has a poor prognosis if the subject score is at least 4.

\section{Scoring System}

The step to produce the scoring system are scoring for each variable, transforming the data according to the score, making the total score variable, making the scoring model, calculating the probability of the subject having cognitive impairment, and making the scoring card (10).

From the analysis, we got the equation: $\mathrm{Y}=-4,164+1,249$ of total SSP GKH score $(95 \% \mathrm{CI}=1,856-6,542)$.

The probability of a subject with cognitive impairment can be seen in Table 6. From these results we can create a scorecard named SSP GKH (table 7).

\section{DISCUSSION}

This study is a prognostic study to determine predictors of cognitive impairment in HIV patients. The research design used is case control because it is considered in accordance with the purpose of the researcher. Consecutive sampling technique is used because this technique is the best and easiest nonprobability sampling (11).

The sample size is determined by the formula of the sample for prognostic research with the output of the categorical form of the dichotomes. The value of the proportion of securities in the control group was determined based on preliminary research. The minimum sample size required is 32 people per group based on the calculations performed. The subjects obtained are allocated into two groups; first group with normal MOCA-Ina results called controls, and second group with abnormal MOCA-Ina are referred to as cases. The case and control groups in this study each had 39 subjects.

Statistical analysis was performed using SPSS 22.0 program. Bivariate analysis was done by Chi-square test. Parameters with OR $>1$ and p values $<0.25$ in bivariate analysis will be analyzed using multivariate (backward stepwise method). Parameters with significant multivariate test results will be defined as GKH SSP parameters. Furthermore, these parameters become the prognostic model of GSP SSP whose accuracy depends on calibration and discrimination values. The calibration values were tested by Hosmer and Lemeshow test while discrimination values were tested with Area Under the Curver (AUC). The best model produced will be a scoring system which can be used in daily applications $(10,12)$. 
International Journal of Psychosocial Rehabilitation, Vol. 24, Issue 02, 2020

ISSN: $1475-7192$

The study obtained gender characteristics (Table 1) out of a total of 78 samples, $58 \%$ percent of men and $42 \%$ of women. A multinational-based study (SMART) of 292 samples obtained more men by $48.2 \%$ and females by $41.8 \%$ (13).A HAND study in Singapore received 132 samples with 84.3\% of men and women of 15.7\% (14).

Characteristics of research subjects based on educational level were obtained from a total of 78 samples; $85 \%$ percent for $>12$ years and $15 \%$ for $<12$ years. Studies on HIV infection have shown that individuals with more than 12 years of education have better executive functioning skills than people with $<12$ years of education $(15,14)$.

Two independent variables, namely age and BMI, were not among the predictors of cognitive impairment in this study. BMI has been excluded from predictors at bivariate analysis and age as well. While the vascular risk factor was excluded when the first step of logistic regression analysis was backward stepwise method. In the second step, sex came out of the analysis.

The duration of antiretroviral therapy was a predictor of cognitive impairment in this study. Some literature suggests that duration of antiretroviral administration is a factor in the prognosis of cognitive impairment (16-18). One study found that clinically significant cognitive improvement improvements peaked around 24-36 weeks after combination ART and continued until a year later.

The nadir T lymphocyte was a predictor of cognitive impairment. This is consistent with the literature that suggests when immune suppressed on the inner level, as reflected in nadir CD4. This causes permanently damaged neuronal cells that contribute to $\operatorname{HAND}(19,20)$.

CNS opportunistic infections predict the occurrence of cognitive impairment in this study. HIV infection itself can cause neuropathological changes, CNS opportunistic infections among HIV patients often result in more severe damage than brain structures (21).

Four predictors of this cognitive impairment become parameters of SSP GKH model. After a logistic regression analysis was performed on four GKH SSP parameters (duration of antiretroviral treatment, CNS opportunistic infections, CD4 T lymphocytes, and level of education). From the ROC procedure, SSP GKH has AUC of $80.9 \%$ (95\% CI $=71.1 \%-90.6 \%$ ). AUC value of $80.9 \%$ statistically shows that the SSP GKH model has strong prognostic value.

We found an optimal cut-off point of 3.5 which is also a statistical point of intersection (table 5 and figure 3). This point was derived from the intersection of the sensitivity curve and the specificity curve (Figure 3). At a value of 3.5 SSP GKH has a sensitivity of $74.4 \%$ and a specificity of $79.5 \%$ (table 5).

\section{CONCLUSION}

This study produces the SSP GKH model which has the following equation: SSP GKH=-4.164+1.249 Total Score of SSP GKH. This equation successfully developed into a scorecard that is easily applied in the field. The SSP GKH value of $\geq 3.5$ indicates a poor prognosis in cognitive disorders. The SSP GKH value of $<3.5$ indicates a good prognosis with sensitivity of $74.4 \%$ and a specificity of $79.5 \%$.

The advantages and disadvantages of SSP GKH as a predictor of cognitive impairment in HIV infection is necessary to be studied further by testing external validation. In addition, further research is needed to include simple laboratory, radiological or other comorbid examinations. 


\section{REFERENCES}

[1] Matinella A, Lanzafame M, Bonometti MA, Gajofatto A, Concia E, Vento S, et al. Neurological complications of HIV infection in pre-HAART and HAART era: a retrospective study. Journal of Neurology 2015;262:1317-1327.

[2] Ueda, S., Witaningrum, A.M., Khairunisa, S.Q.,, Nasronudin, Kameoka, M. Transmission dynamics of HIV-1 subtype B strains in Indonesia. Scientific Reports. 2019;9(1),13986

[3] Williams DW, Calderon TM, Lopez L, Carvallo-Torres L, Gaskill PJ, Eugenin EA, et al. Mechanisms of HIV Entry into the CNS: Increased Sensitivity of HIV Infected CD14 ${ }^{+}$CD $16{ }^{+}$Monocytes to CCL2 and Key Roles of CCR2, JAM-A, and ALCAM in Diapedesis. PLoS ONE 2013;8:e69270.

[4] Williams DW, Veenstra M, Gaskill PJ, Morgello S, Calderon TM, Berman JW. Monocytes mediate HIV neuropathogenesis: mechanisms that contribute to HIV associated neurocognitive disorders. Curr HIV Res 2014;12:85-96.

[5] Nightingale S, Winston A, Letendre S, Michael BD, McArthur JC, Khoo S, et al. Controversies in HIVassociated neurocognitive disorders. The Lancet Neurology 2014;13:1139-1151.

[6] Cohen RA, Seider TR, Navia B. HIV effects on age-associated neurocognitive dysfunction: premature cognitive aging or neurodegenerative disease? Alzheimers Res Ther 2015;7:37.

[7] Barnes DE, Covinsky KE, Whitmer RA, Kuller LH, Lopez OL, Yaffe K. Predicting risk of dementia in older adults: The late-life dementia risk index. Neurology 2009;73:173-179.

[8] Exalto LG, Quesenberry CP, Barnes D, Kivipelto M, Biessels GJ, Whitmer RA. Midlife risk score for the prediction of dementia four decades later. Alzheimer's \& Dementia 2014;10:562-570.

[9] Windarto, Anggriani, N.Global stability for a susceptible-infectious epidemic model with fractional incidence rate. Applied Mathematical Sciences. 2015;9(73-76), pp. 3775-3788

[10] Harnanti, D.V., Hidayati, A.N., Miftahussurur, M.Concomitant sexually transmitted diseases in patients with diagnosed HIV/AIDS: A retrospective study. African Journal of Infectious Disease. 2019; 12 (Special Issue 1), pp.83-89

[11] Sinansari, R., Bambang Prajogo, E.W., Widiyanti, P.In silico screening and biological evaluation of the compounds of justicia gendarussa leaves extract as interferon gamma inducer: A study of anti human immunodeficiency virus (HIV) development. African Journal of Infectious Diseases.2018;12(Special Issue 1), pp. 140-147

[12] Yunifiar, M.Q., Kotaki, T., Witaningrum, A.M., (...), Nasronudin, N., Kameoka, M.Sero- and Molecular Epidemiology of HIV-1 in Papua Province, Indonesia. Acta medica Indonesiana. 2017; 49(3), pp. 205-214

[13] Wright EJ, Grund B, Robertson K, Brew BJ, Roediger M, Bain MP, et al. Cardiovascular risk factors associated with lower baseline cognitive performance in HIV-positive persons. Neurology 2010;75:864873.

[14] Chan LG, Kandiah N, Chua A. HIV-associated neurocognitive disorders (HAND) in a South Asian population - contextual application of the 2007 criteria. BMJ Open 2012;2:e000662.

[15] Cross S, Onen N, Gase A, Overton ET, Ances BM. Identifying risk factors for HIV-associated neurocognitive disorders using the international HIV dementia scale. J Neuroimmune Pharmacol 2013;8:1114-1122.

[16] Heaton RK, Franklin DR, Ellis RJ, McCutchan JA, Letendre SL, Leblanc S, et al. HIV-associated neurocognitive disorders before and during the era of combination antiretroviral therapy: differences in rates, nature, and predictors. J Neurovirol 2011;17:3-16.

[17] Cysique LA, Vaida F, Letendre S, Gibson S, Cherner M, Woods SP, et al. Dynamics of cognitive change in impaired HIV-positive patients initiating antiretroviral therapy. Neurology 2009;73:342-348.

[18] Cysique LA, Murray JM, Dunbar M, Jeyakumar V, Brew BJ. A screening algorithm for HIV-associated neurocognitive disorders. HIV Med 2010;11:642-649.

[19] Munoz-Moreno JA, Fumaz CR, Ferrer MJ, Prats A, Negredo E, Garolera M, et al. Nadir CD4 cell count predicts neurocognitive impairment in HIV-infected patients. AIDS Res Hum Retroviruses 2008;24:13011307.

[20] Ellis RJ, Badiee J, Vaida F, Letendre S, Heaton RK, Clifford D, et al. CD4 nadir is a predictor of HIV neurocognitive impairment in the era of combination antiretroviral therapy. AIDS (London, England) 2011;25. 
[21] Levine AJ, Hinkin CH, Ando K, Santangelo G, Martinez M, Valdes-Sueiras M, et al. An exploratory study of long-term neurocognitive outcomes following recovery from opportunistic brain infections in HIV+ adults. J Clin Exp Neuropsychol 2008;30:836-843.

[22] Abdelgawad, M.A. Synthesis and antimicrobial evaluation of N-(3-benzoxazol-2-yl-phenyl)acrylamide(2018) International Journal of Pharmaceutical Research, 10 (4), pp. 461-465. https://www.scopus.com/inward/record.uri?eid=2-s2.0-

85062387451\&doi=10.31838\%2fijpr\%2f2018.10.04.070\&partnerID=40\&md5=269cbd06296ddff14baa9c 45d72e7e33

[23] Pinzon, r. T. \& sanyasi, . R. D. L. R. (2018) is there any benefit of citicoline for acute ischemic stroke ? Systematic review of current evidences. Journal of Critical Reviews, 5 (3), 1114. doi:10.22159/jcr.2018v5i3.24568

[24] Patel RR, Patel JK. "Novel Technologies of Oral Controlled Release Drug Delivery System." Systematic Reviews in Pharmacy 1.2 (2010), 128-132. Print. doi:10.4103/0975-8453.75054 
TABLES

Table1:Characteristics of Subjects

\begin{tabular}{|c|c|c|c|c|c|c|}
\hline & \multicolumn{4}{|c|}{ MOCA-Ina } & \multirow{3}{*}{$p$} & \multirow{3}{*}{ OR (95\% CI) } \\
\hline & \multicolumn{2}{|c|}{ Case } & \multicolumn{2}{|c|}{ Control } & & \\
\hline & $\mathbf{N}$ & $\%$ & $\mathbf{N}$ & $\%$ & & \\
\hline \multicolumn{7}{|l|}{ Sex } \\
\hline Woman & 20 & 60,6 & 13 & 39,4 & 0,10 & 2,11 \\
\hline Man & 19 & 42,2 & 26 & 57,8 & 9 & $(0.84-5.26)$ \\
\hline \multicolumn{7}{|l|}{ Age } \\
\hline$\geq 40$ years & 14 & 35,9 & 12 & 30,8 & 0,631 & 1,26 \\
\hline$<40$ years & 25 & 64,1 & 27 & 69,2 & & $(0,49-3,237)$ \\
\hline \multicolumn{7}{|c|}{ Level of Education } \\
\hline$\leq 12$ years & 37 & 94,9 & 29 & 74,4 & 0,01 & 6,38 \\
\hline$>12$ years & 2 & 5,1 & 10 & 25,6 & 2 & $(1,29-31.41)$ \\
\hline
\end{tabular}

Table2:Characteristics of Subjects Based on Clinical Data

\begin{tabular}{lcccc}
\hline Variables & $\begin{array}{c}\text { Case Group } \\
(\mathrm{n}=39)\end{array}$ & $\begin{array}{c}\text { Control } \\
\text { Group } \\
(\mathrm{n}=39)\end{array}$ & Total & $\begin{array}{c}\text { p } \\
\text { Value }\end{array}$ \\
& & & & \\
\hline ART Duration & $27(58,7 \%)$ & $19(41,3 \%)$ & 46 & 0,020 \\
$\leq 1$ years & $12(37,5 \%)$ & $20(62,5 \%)$ & 32 & \\
$>1$ years & & & & \\
Number ofCD4 & $35(54,7 \%)$ & $29(45,3 \%)$ & 64 & 0,033 \\
$\leq 200$ cell/mm ${ }^{3}$ & $4(28,6 \%)$ & $10(71,4 \%)$ & 14 & \\
$>200$ cell/ mm ${ }^{3}$ & & & & \\
Vascular risk factors & $16(64,0 \%)$ & $9(36,0 \%)$ & 25 & 0,089 \\
Yes & $23(43,4 \%)$ & $30(56,6 \%)$ & 53 & \\
No & & & & \\
CNS opportunistic infections & $6(75,0 \%)$ & $2(25,0 \%)$ & 8 & 0,120 \\
Yes & $33(47,1 \%)$ & $37(52,9 \%)$ & 70 & \\
No & & & & \\
Body Mass Index (BMI) & $10(55,6 \%)$ & $8(25,0 \%)$ & 18 & 0,591 \\
Abnormal & $29(48,3 \%)$ & $31(51,7 \%)$ & 60 & \\
Normal & $12,35 \pm 10,29$ & $7,76 \pm 8,33$ & & 0,034 \\
BDI & & & & \\
\hline
\end{tabular}


International Journal of Psychosocial Rehabilitation, Vol. 24, Issue 02, 2020

ISSN: $1475-7192$

Table3: Odds Ratio Value and 95\% CI Candidate of SSP GKH Parameters

\begin{tabular}{clcc}
\hline \multicolumn{1}{c}{$\mathbf{N}$} & Variabels & Odds Ratio (95 \% CI) & p Value \\
o. & & & \\
\hline 1. & Level of Education & $6,38(1,29-31.41)$ & 0.012 \\
2. & ART Duration & $3,05(1,16-7,93)$ & 0.020 \\
3. & Age & $1,26(0,49-3,24)$ & 0.631 \\
4. & Sex & $2,11(0.84-5.26)$ & 0.109 \\
5. & T CD4 lymphocytes & $4,14(1,04-16,44)$ & 0.033 \\
6. & Vascular risk factors & $2,32(0,87-6,18)$ & 0.089 \\
7. & CNS opportunistic infections & $6,38(1,29-31,40)$ & 0.012 \\
8. & Body Mass Index (BMI) & $1,34(0,46-3,85)$ & 0.591 \\
\hline
\end{tabular}

Table4:Logistic Regression Analysis WITH Backward Stepwise Method

\begin{tabular}{|c|c|c|c|c|c|c|c|}
\hline & & B & S.E. & Wald & $\mathrm{df}$ & Sig. & $\begin{array}{c}\operatorname{Exp}( \\
)\end{array}$ \\
\hline \multirow{7}{*}{ 苛 } & Education(1) & 1,933 & ,879 & 4,831 & 1 & ,028 & $\begin{array}{r}6,90 \\
9\end{array}$ \\
\hline & $\mathrm{CD} 4(1)$ & 1,563 & ,854 & 3,352 & 1 & ,067 & $\begin{array}{r}4,77 \\
5\end{array}$ \\
\hline & OPPCNS(1) & 2,164 & 1,075 & 4,050 & 1 & ,044 & $\begin{array}{r}8,70 \\
8\end{array}$ \\
\hline & $\begin{array}{l}\text { ARTDuration } \\
\text { (1) }\end{array}$ & 1,238 & ,555 & 4,979 & 1 & ,026 & $\begin{array}{r}3,45 \\
0\end{array}$ \\
\hline & Vasculer(1) & ,112 & ,652 & ,030 & 1 & ,863 & $\begin{array}{r}1,11 \\
9\end{array}$ \\
\hline & $\operatorname{Sex}(1)$ & ,729 & ,570 & 1,636 & 1 & ,201 & 2,07 \\
\hline & Constant & $-4,356$ & 1,270 & 11,770 & 1 & ,001 & ,013 \\
\hline \multirow{5}{*}{ 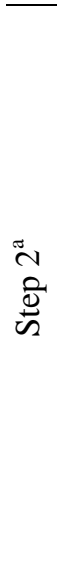 } & Education(1) & 1,957 & ,869 & 5,075 & 1 & ,024 & $\begin{array}{r}7,07 \\
6\end{array}$ \\
\hline & CD4(1) & 1,600 & 828 & 3,737 & 1 & ,053 & $\begin{array}{r}4,95 \\
4\end{array}$ \\
\hline & OPPCNS(1) & 2,228 & 1,015 & 4,817 & 1 & ,028 & $\begin{array}{r}9,28 \\
0\end{array}$ \\
\hline & $\begin{array}{l}\text { ARTDuration } \\
\text { (1) }\end{array}$ & 1,237 & ,555 & 4,969 & 1 & ,026 & $\begin{array}{r}3,44 \\
7\end{array}$ \\
\hline & $\operatorname{Sex}(1)$ & ,708 & ,556 & 1,622 & 1 & ,203 & 2,03 \\
\hline
\end{tabular}


International Journal of Psychosocial Rehabilitation, Vol. 24, Issue 02, 2020 ISSN: $1475-7192$

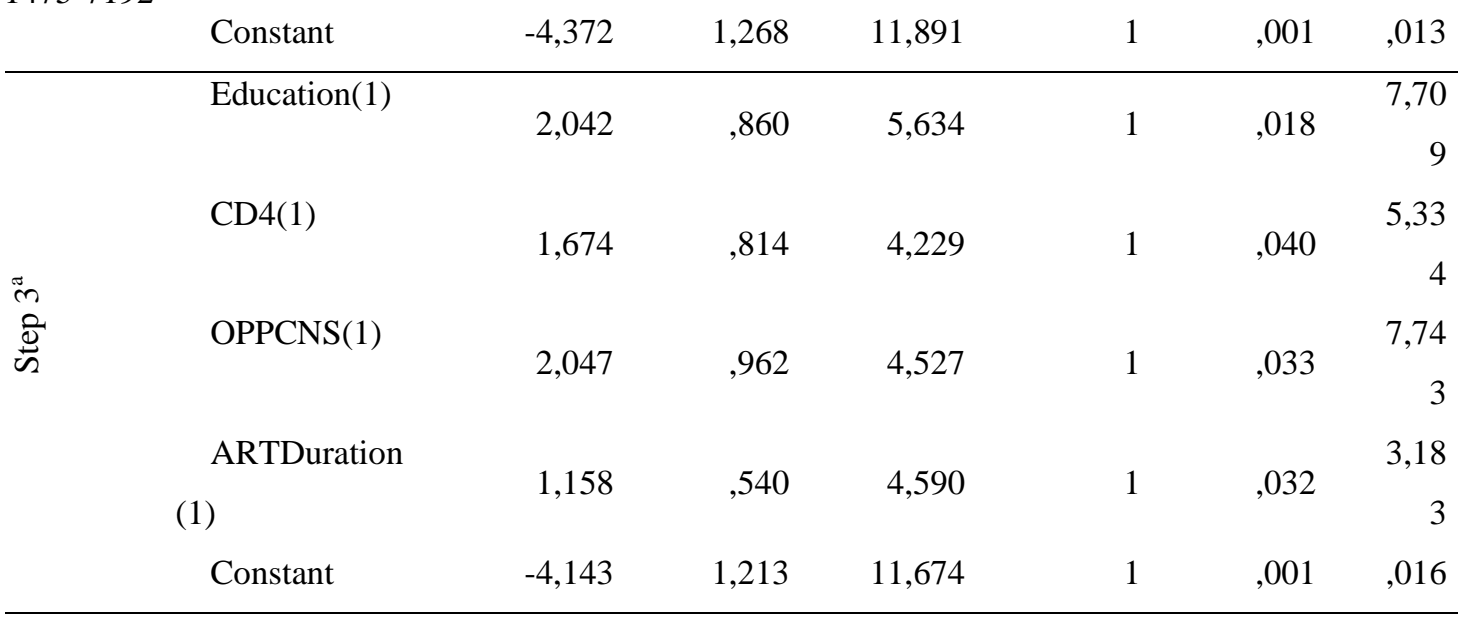

Table5:The Value of Sensitivity and Specificity of Soetomo Score From Some Alternative Cut Points

\begin{tabular}{c|c|c|c}
\hline $\begin{array}{c}\mathrm{N} \\
0 .\end{array}$ & Positive if Greater Than or Equal $\mathrm{To}^{\mathrm{a}}$ & Sensitivity & Specificity \\
\hline 1 & 0,0 & 1,000 & 0,000 \\
2 & 1,5 & 1,000 & 0,128 \\
3 & 2,5 & 0,897 & 0,333 \\
4 & 3,5 & 0,744 & 0,795 \\
5 & 4,5 & 0,154 & 0,974 \\
6 & 6,0 & 0,000 & 1,000 \\
\hline
\end{tabular}

Table6:Total Score of SSP GKH

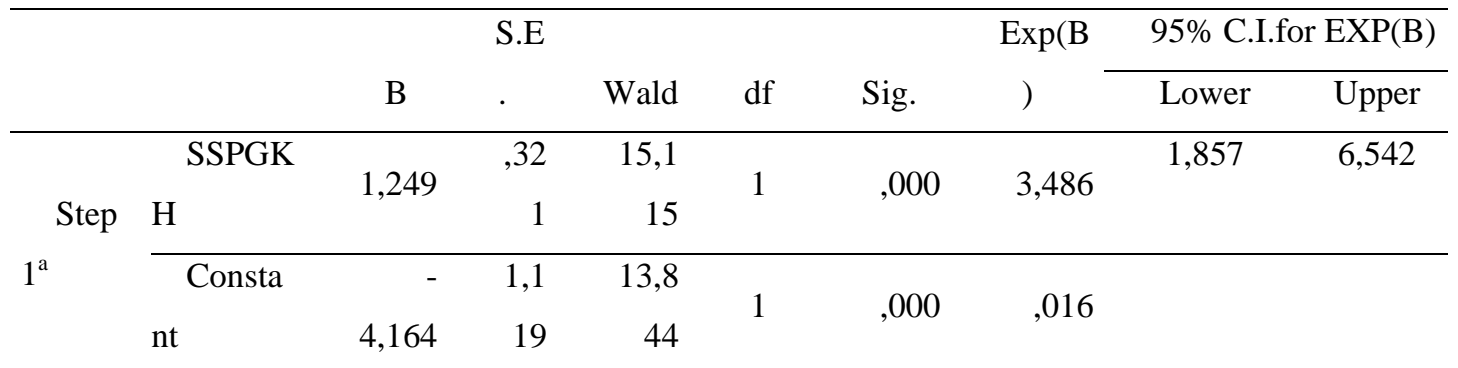

Table7:The Probability of a Subject To Have a Cognitive Impairment on Each Score

\begin{tabular}{ccccc}
\hline Patient & Constants & Coefficient & SSP GKH & Probability \\
Score & & & equation & (\%) \\
\hline 0 & $-4,164$ & 1,249 & $-4,164$ & 1,53
\end{tabular}


International Journal of Psychosocial Rehabilitation, Vol. 24, Issue 02, 2020

ISSN: $1475-7192$

$\begin{array}{ccccc}1 & -4,164 & 1,249 & -2,915 & 5,14 \\ 2 & -4,164 & 1,249 & -1,666 & 15,89 \\ 3 & -4,164 & 1,249 & -0,417 & 39,72 \\ 4 & -4,164 & 1,249 & 0,832 & 69,67 \\ 5 & -4,164 & 1,249 & 2,081 & 88,9\end{array}$

